\title{
DESARROLLO ECONÓMICO Y/O BUEN VIVIR: DILEMA ACTUAL DEL LATINOAMERICANO
}

\author{
Wolney Roberto Carvalho' \\ Félix Pablo Friggeri
}

\section{Resumen}

Desarrollo y Buen Vivir aparecen en el horizonte de los gobiernos latinoamericanos que se autoproclaman como populares y que visan la integración regional. El primero, nacido en el seno del capitalismo, fue adoptado por los gobiernos de izquierda como sinónimo de condición y posibilidad de un proceso de independización económica y política. El segundo, emergido de las luchas indígenas y del proceso de politización de lo étnico, se ha manifestado desde los años ochenta hasta plasmarse como principios constitucionales en algunos países. En ese sentido, este artículo pretende demonstrar cómo ambas visiones aparecen en conflicto. $\mathrm{Si}$, en la actual fase del capitalismo en Latinoamérica, se muestra una fuerte preocupación de los gobiernos en cuanto a la integración económica, se constata, en el presente trabajo, que la garantía de los derechos humanos como la salud, vivienda, educación y alimentación está lejos de proporcionar el Buen Vivir a las personas marginalizadas, porque la racionalidad del modelo desarrollista está direccionado hacia la producción de ganancias, en lugar de orientarse hacia la producción de la vida.

Palabras clave: América Latina. Desarrollo Económico. Movimientos Sociales,

Dr. en Sociologia Política y Mestre en Economia (UFSC) - Universidad Federal de Santa Catarina (UFSC), Brasil. Profesor del Curso de Ciencias Económicas y del Instituto Latinoamericano de Economía, Sociedad y Política (ILAESP/ UNILA).E-mail:wolneyc@hotmail.com

2 Dr. en Ciencias Sociales - Universidad Nacional de Entre Ríos (UNER), Argentina, Profesor del Curso de Relaciones Internacionales (UNILA) e Director del Instituto Latinoamericano de Economía, Sociedad y Política (ILAESP/UNILA). E-mail: felix.friggeri@unila.edu.br 


\section{INTRODUCCIÓN}

El discurso sobre el desarrollo fue dominando la escena mundial y, en un especial sentido, la escena latinoamericana, para afirmarse fuertemente en la post Segunda Guerra Mundial y con fuerza en las décadas de los cincuenta y sesenta.

Por lo tanto,

"Desarrollo" fue, sobre todo en el debate latinoamericano, el término clave de un discurso político asociado a un elusivo proyecto de desconcentración y redistribución del control del capital industrial, en la nueva geografía que se configuraba en el capitalismo colonial moderno, al término de la Segunda Guerra Mundial. En un primer momento, tal discurso fue virtualmente oficial. Sin embargo, pronto dio lugar a complejas y contradictorias cuestiones que produjeron una intensa discusión, con eco mundial, que se fue desplegando en estrecha relación con los conflictivos y violentos movimientos de la sociedad. Esto llevó a procesos inconducentes o a cambios relativamente importantes, pero inacabados, en la distribución de poder. (Quijano, 2010: 48-49)

De acuerdo con Escobar (2011), es importante una advertencia que da actualidad al análisis de este concepto y del proyecto político-económico consecuente, a pesar de su relativo ocaso en las décadas fuertemente neoliberales: es que en la actual realidad política latinoamericana los llamados "gobiernos progresistas han revitalizado el desarrollismo a nombre del cambio radical" y que aunque se presenten como una superación del neoliberalismo, están arrastrando muchos elementos de ese período a lo que se suman "trampas del desarrollismo convencional".

Por eso, no se puede olvidar que

El desarrollo es un proyecto tanto económico (capitalista e imperial) como cultural. Es cultural en dos sentidos: surge de la experiencia particular de la modernidad europea; y subordina las demás culturas y conocimientos, las cuales pretende transformar bajo principios occidentales. El desarrollo privilegia el crecimiento económico, la explotación de recursos naturales, 
la lógica del mercado y la búsqueda de satisfacción material e individual por sobre cualquier otra meta. (Escobar, 2011:307)

Escobar todavía apunta a uno de los grandes defectos del modelo de desarrollo: ser "modernizante" (Escobar, 2011: 310). Así, se utilizando de "la retórica de la modernidad" impusieron e imponen violentamente proyectos imperialistas que hablan "de salvar al otro de sus propios barbarismos" (Grosfoguel, 2006: 38).

El otro gran defecto del modelo de desarrollo es su occidentalismo y la capacidad de ocultar las potencialidades epistémicos-políticas de las mayorías populares del "mundo subdesarrollado".

En ese sentido,

La superioridad atribuida al conocimiento europeo en muchas esferas de la vida era un aspecto importante de la colonialidad del poder en el sistema mundo moderno/colonial. Los conocimientos subalternos se excluían, omitían, silenciaban o ignoraban. Éste no es un llamado a una misión de rescate de la autenticidad de tipo fundamentalista o esencialista. El punto aquí es poner la diferencia colonial en el centro de un proceso de producción de conocimiento. Los conocimientos subalternos son aquellos que se encuentran en la intersección de lo tradicional y lo moderno. Son formas de conocimiento híbridas, transculturales, no simplemente en el sentido del sincretismo tradicional o 'mestizaje', sino en el que les da Aimé Cesaire de 'armas milagrosas' o lo que he llamado 'complicidad subversiva' contra el sistema. Son modalidades de resistencia que resignifican y transforman las formas de conocimiento dominantes desde el punto de vista de la racionalidad no eurocéntrica de subjetividades subalternas que piensan desde epistemologías fronterizas. Constituyen lo que Walter Mignolo llama una crítica de la modernidad desde las experiencias geopolíticas y las memorias de la colonialidad. Según Mignolo, éste es un nuevo espacio que merece ser explorado más a fondo tanto como una nueva dimensión crítica de la modernidad/colonialidad y, al mismo tiempo, como un espacio desde donde pueden diseñarse nuevas utopías. (Grosfoguel, 2006: 37-38) 
Estos aportes son importantes para que, sin descalificar el valor de muchos de los planteos y realizaciones de varios gobiernos latinoamericanos - que se puede decir que han configurado una de las etapas más interesantes de nuestra historia regional -, sea posible verificar cuáles son los elementos incoherentes dentro de una perspectiva de cambio social profundo (algunos lo llaman revolución) y de integración latinoamericana contrahegemónica.

Se observa en la actual fase del capitalismo en Latinoamérica una fuerte preocupación de los gobiernos por el desarrollo y la integración económica de nuestro continente, pero la garantía de los derechos humanos como la salud, habitación, educación y alimentación está lejos de proporcionar el Buen Vivir a la gente marginalizada, y eso se debe principalmente a la racionalidad del modelo desarrollista que continua direccionada hacia la producción de ganancias.

En ese sentido, desarrollo y Buen Vivir aparecen en el horizonte de los gobiernos latinoamericanos que se autoproclaman como populares y que visan la integración regional. No obstante, como se demostrará a lo largo de este artículo, estos dos modelos no se encuentran armonizados ya que parten de bases epistémicas distintas.

\section{LOS PRIMEROS APORTES DELDESARROLLO ECONÓMICO}

La discusión acerca del desarrollo económico surge primeramente con David Ricardo. Basado en la preocupación de los crecientes aumentos salariales en el ámbito industrial y sus reflejos sobre las ganancias, Ricardo (1982) desarrollará un sistemático estudio partiendo de una crítica a los grandes propietarios de tierras, destacando las limitaciones agrícolas de Inglaterra y sus impactos sobre la dinámica de la acumulación del capital.

Es importante percibir que su primera preocupación está vinculada a la concentración de las mejores tierras inglesas en manos de grandes terratenientes. Esas tierras eran, poco a poco, cultivadas por los capitalistas agrícolas, que a su vez producían alimentos destinados a los crecientes mercados, en especial aquellos direccionados al consumo de los trabajadores industriales. Así, si las primeras parcelas de tierras explotadas por los capitalistas agrícolas no generaban renta a los propietarios - debido al hecho de la gran disponibilidad de tierras y al pequeño número de los capitalistas 
agrícolas existentes, consideración adoptada por Ricardo - la creciente industrialización de los principios del siglo XIX estimulará la producción capitalista en la agricultura, y cada vez más en especial en la medida en que el número de trabajadores industriales aumenta, repercutiendo en el aumento de la demanda por alimentos. Se encuentra allí el centro de las preocupaciones de Ricardo en un primero momento, pues al aumentar la demanda por alimentos de la parte de los trabajadores eso iba a reflejarse en el surgimiento de un mayor número de capitalistas en el ámbito de la agricultura. A su vez, las tierras de buena calidad disponibles, las más fértiles, disminuirían, proporcionando a los propietarios de tierras - frente a una demanda mayor por los nuevos capitalistas agrícolas para producir en las tierras más fértiles - una renta de la tierra. Vale observar que esa renta apropiada por parte de los propietarios de tierras, es el diferencial de la producción entre la tierra más fértil y la menos fértil cultivadas - como se nota, para una misma cuantidad de dispendio en medio de producción y mano de obra, la producción es menor en esa última cuando se compara con la primera. Dado eso,

Se todas as terras tivessem as mesmas características, se fossem ilimitadas na quantidade e uniformes na qualidade, seu uso nada custaria, a não ser que possuíssem particulares vantagens de localização. Portanto, somente porque a terra não é ilimitada em quantidade nem uniforme na qualidade, e porque, com o crescimento da população, terras de qualidade inferior ou desvantajosamente situadas são postas em cultivo, a renda é paga por seu uso. (RICARDO, 1982,66)

En ese sentido, cuanto mayor el cultivo de tierras de menor productividad, de menor fertilidad, mayor es la renta de la tierra exigida a los capitalistas que actúan produciendo en las tierras más fértiles. El resultado de esa dinámica era la perecuación de la tasa de ganancia de los capitalistas agrícolas, la cual a su vez, disminuía con el aumento de los cultivos de tierras cada vez menos fértiles. Por otra parte, se observa en Ricardo (1982) que los precios de los productos agrícolas también eran definidos por la producción en las tierras menos fértiles. En esa dirección, si la producción en las tierras menos fértiles - para una cierta cantidad de capital y trabajo- es menor, eso significa que la productividad es menor, y que además, los precios de las 
mercancías agrícolas producidas serán mayores, tanto cuanto mayor sea la demanda por esos bienes.

De esa forma, adoptando la hipótesis de los precios constantes para las mercancías producidas en el ámbito industrial, Ricardo (1982) entenderá que cuanto más grandes sean las disposiciones de los capitalistas para realizar inversiones, mayores tendrían que ser los gastos en la contratación de la mano de obra. Así, con base en esta consideración, una demanda aumentada por mano de obra incidiría rápidamente - a corto plazo - sobre los salarios, colocándolos por encima del precio natural del trabajo (lo cual corresponde a los precios de los medios de subsistencia consumidos por los trabajadores) $\mathrm{y}$, eso a su vez, abriría posibilidades para que los trabajadores disfrutaran de mejores condiciones de vida aumentando incluso la población.

Como se puede percibir, ese aumento poblacional va en dirección a un aumento global sobre la demanda por las mercancías agrícolas, ocasionando así - considerándose la productividad decreciente del suelo inglés - un aumento de los precios de los productos agrícolas, como también de la renta de la tierra.

Con base en lo expuesto anteriormente, y a partir de Ricardo (1982), se verifica un aumento del precio natural del trabajo para un nivel superior al anterior, y con eso, el equilibrio entre ese precio natural del trabajo y los salarios se establecerá en un nivel más alto. Así, si en última instancia los gastos de los trabajadores con la subsistencia aumentan, resultado final del aumento de las inversiones capitalistas, ahora tendrán los detentores del factor capital que aumentar los gastos con los salarios, incluso si para aumentar la producción sea necesario aumentar el número de trabajadores contratados.

De esta forma, como los precios de las mercancías producidas en la esfera industrial son constantes, el aumento de las inversiones será acompañado de una caída de las ganancias, pues

Se o trigo e os produtos manufaturados fossem vendidos sempre pelos mesmos preços, os lucros seriam altos ou baixos, na medida em que fossem baixos ou altos os salários. Mas, embora o preço do trigo aumente quando mais trabalho for necessário para produzí-lo, essa causa não elevará o preço dos artigos manufaturados cuja produção não exigiu maior quantidade de trabalho. Se, portanto, os salários permanecerem os mesmos, os lucros dos fabricantes também não se 
alterarão. Se, no entanto, como é absolutamente certo, os salarios aumentarem com o aumento do trigo, então os lucros necesariamente diminuirão. (RICARDO,1982, 91)

Por eso, Ricardo propuso abolir las leyes que imposibilitaban la importación de los cereales, creadas por los grandes terratenientes con el objetivo de aumentar la renta de las tierras.

La propuesta de abolición de la Ley de los Cereales estuvo, sobre todo, volcada hacia la resolución de la caída de las ganancias de los capitalistas industriales. Una vez liberalizada la importación de los cereales y aumentando la oferta en Inglaterra, los precios de los cereales consumidos por los trabajadores disminuirían, reduciendo con eso el precio natural del trabajo y la posibilidad de los capitalistas de pagar menores salarios. Además podrían importar materias primas y aumentar el mercado para los productos industriales ingleses.

Así, es importante destacar que las preocupaciones de Ricardo pueden ser traducidas como preocupaciones acerca del desarrollo económico, ya que se refieren a análisis de cómo los hombres organizan la producción, distribución y acumulación de la riqueza social producida.

Entretanto, hay que destacar que Ricardo (1982), como el más digno sucesor de Smith, utilizará un instrumental conceptual presentado por este último para observar las relaciones socio-económicas entre los hombres. Dicho instrumental tiene por base que la producción de la riqueza, así como la distribución y acumulación de la misma se ampara con base en la propiedad de los factores de producción, los cuales a su vez corresponden a la tierra, el capital y el trabajo.

De esta manera, la riqueza producida siempre será originada por los respectivos factores productivos - la tierra, el capital y el trabajo -, y suya distribución aparecerá en la forma rendimientos de dichos factores. Así, al factor productivo tierra le corresponde la renta de la tierra; al factor productivo capital le corresponden las ganancias y el interés como rendimientos; finalmente, al factor productivo trabajo le es asignado el salario.

Se puede percibir que, a pesar de que Smith y Ricardo atribuyen importancia a la teoría del valor trabajo, e incluso que este último la profundizó, la adopción de esa teoría fue relegada en el momento de analizar la producción, distribución y acumulación de la riqueza, y eso se ratifica 
dado que los hombres ya no representan el elemento central de la creación de riquezas, ósea, son desplazados por los factores productivos.

No se puede olvidar que entre esos factores productivos, como destaca muy bien Ricardo, el capital es el principal responsable de la dinámica del desarrollo, y por eso mismo, su rendimiento - la ganancia - debe ser siempre preservado.

\section{POTENCIALIDADES Y LÍMITES DEL PLANTEO LATINOA- MERICANO DE DESARROLLO}

De acuerdo con Wallerstein (1999), es prácticamente imposible el desarrollo de Latinoamérica, ya que lo que se desarrollan no son países o regiones aisladamente, sino la economía-mundo capitalista. Esa economía-mundo se encuentra basada en una estructura orgánica compuesta de una región central, una semi-periférica y otra periférica, $\mathrm{y}$, a pesar de haber sido ratificada después del siglo XIX, tiene sus fundamentos en el siglo XVI.

En este orden de ideas,

Em primeiro lugar começou a se formar no século XVI, tendo como centro o continente europeu, uma economía-mundo capitalista. Desde o começo, isso envolveu o estabelecimento de processos de produção integrados que podemos chamar de cadeias de mercadorias. Essas cadeias de mercadorias tenderam a transpor as fronteiras públicas existentes. A mais-valia total extraída nelas em nenhum momento se distribuiu equanimemente em termos de localização geográfica da criação de mais-valia, tendo sempre se concentrado, num grau desproporcional, em algumas e não em outras zonas. Designamos por "periferias" as zonas que perderam na ditribuição de mais-valia para as zonas do "centro". Enquanto no começo do processo histórico parecia haver pouca diferença de riqueza econômica entre as diferentes áreas geográficas, o fluxo de mais-valia do mero período de um século foi suficiente para criar uma visível distinção entre centro e periferia em termos de três criterios: a acumulação do capital, a organização social dos processos de produção locais e a organização política das estruturas estatais em criação. (Wallerstein, 2006, 128) 
Se destaca que, dichos fundamentos buscan maximizar los cálculos que hacen los capitalistas acerca de las ganancias, ósea, desde hace 500 años ellos analizan la importancia de los costos de las transacciones y de los costos de la fuerza de trabajo. Eso implica que, como la búsqueda de ganancias es la orientación primera, esos referidos costos son determinantes para las decisiones de inversión. Entonces, cuando los costos de las transacciones son los más importantes y cuando representan un dispendio considerable para los capitalistas, se verifica una tendencia de concentración de la producción capitalista en zonas de fácil comercialización de las mercancías, es decir, en zonas o regiones que presentan buenos y grandes mercados consumidores y que se localizan en espacios de fácil transporte marino, fluviales, aeroportuarios y de ferrocarriles. Por otro lado, cuando los costos de la fuerza de trabajo representan mayores gastos para los capitalistas, estos se dirigen hacia regiones más periféricas.

Dado eso, se percibe a través de Wallerstein (1999) que ese movimiento de centralización y descentralización de los emprendimientos con base a los dos costos capitalistas, puede ser analizado a través del ciclo de Kondratieff. Cada ciclo corresponde en promedio a 50-60 años de actividad económica mundial, siendo que en los primeros 25-30 años, en la llamada fase A del ciclo, los costos de transacción son los más importantes y la tasa de ganancia en general es alta en función de los aumentos de productividad. En ese período se observa una fuerte concentración de las empresas en las zonas centrales de la economía-mundo, a ejemplo del periodo de la reconstrucción de Europa, lo cual posibilito nuevos espacios para la acumulación capitalista a cargo de Los Estados Unidos. Vale recordar que esa fase fue denominada de compromiso keynesiano, la cual se caracterizó por una fuerte participación estatal en el ámbito económico y en la manutención del estado de bienestar social.

La segunda fase del referido ciclo de la economía-mundo, la fase B, corresponde a la caída de las tasas de ganancia. Conforme Wallerstein (2003), la recuperación de la producción en Japón y Europa y la creciente productividad en esos países provocó un aumento en la producción mundial y simultáneamente una competencia con las empresas estadounidenses, en especial en los grandes sectores industriales como la industria de acero, de vehículos automotores y productos electrónicos a principios de los años 60 . 
Además, la necesidad del creciente financiamiento de los gastos militares de Estados Unidos, exigieron el fin del padrón oro en 1973, a lo cual estuvo asociado el primer choque de petróleo.

En ese momento, lo que se verifica es una dispersión considerable de empresas hacia las zonas más periféricas buscando reducir los costos de la fuerza de trabajo, puesto que

(...) a produção mudou sensivelmente de lugar, de regiões em que se pagavam altos salarios para regiões onde os salários eram menores (fenômeno que se denomina fuga de fábricas). Pode-se notar que tais mudanças ocorreram no mundo por volta de 1970 . Pudemos assistir a uma escalada vertiginosa das atividades especulativas, naturalmente bastante lucrativas para um grupo de pessoas relativamente pequeno, ao menos até a explosão da bolha. Verificaram-se grandes deslocamentos da produção da América do Norte, da Europa e do Japão em direção a outras partes do sistema-mundo, consideradas desde então em vías de industrialização, portanto, de desenvolvimento. Uma outra maneira de caracterizar esses acontecimentos é afirmar que os países semiperiféricos passaram a abrigar as indústrias que se tornaram menos rentáveis. (Wallerstein, 2003,78)

Así, las décadas que seguirán después de los 70 fueron de expansión de empresas multinacionales alrededor del planeta, empresas oriundas principalmente de los países centrales que visaban restablecer las bajas tasas de ganancia mediante la adquisición de una fuerza de trabajo a un costo más bajo.

Se observa en muchos casos, que esas grandes empresas compiten en el marco del mercado mundial, y más allá de buscar la reducción de los costos de la fuerza de trabajo en las zonas semi-periféricas o periféricas, se aproximaron a los mercados ya conquistados en décadas pasadas - y con eso, redujeron también los costos de transacción - o terminantemente conquistaron nuevos mercados y nuevas fuentes de materia prima.

Lo que se verifica es una deslocalización hacia los nuevos países industrializados de la llamada zona semi-periférica como Corea del Sur, Hong Kong, Taiwán y Singapur, Brasil, México, Argentina, y después de los años 90 Rusia, India, China y actualmente países muy periféricos como Bangladesh. 
En todos los Estados-nación, esas empresas fueron exentas de impuestos y tributos y/o beneficiadas con subsidios visando promover el desarrollo económico. No obstante, si el marco de la estructura del capitalismo mundial se fundamenta en una estructura jerárquica, compuesta por las zonas central, semi-periférica y periférica, tras la cual se encuentra una división internacional del trabajo, lo mismo se verifica en los marcos de cada Estado-nación.

A partir de esta reflexión, se puede comprender por qué, en un primer momento, las empresas llegadas a tierras latinoamericanas se instalaron cerca de las principales ciudades o centros comerciales y financieros. La deslocalización hacia las zonas periféricas o semi-periféricas de la economía mundial no implica necesariamente la instalación de la estructura productiva en rincones aislados. Claro está que muchas de las fuentes de materia prima se encontraban y se encuentran en las zonas rurales de esos países, pero el procesamiento en general se dio en las grandes ciudades o cerca de ellas, donde se encontraba una fuerza de trabajo ya calificada y con un costo menor que en los países centrales.

Así, en buena medida se desarrollaron las principales regiones y las principales ciudades de Latinoamérica después de los años 70, fruto de la búsqueda por la maximización de ganancias, de la restauración del descenso de los beneficios en el centro. Se añade a esto, el creciente papel de los Estados nacionales que asumieron los costos de la infraestructura básica necesaria a la reproducción del capital y, estimularon el fortalecimiento de la burguesía nacional en determinado sectores. Además,

Finalmente, para realizarem lucros maiores e não menores, os capitalistas precisam de monopólios, pelo menos de monopólios relativos, em certos cantos da vida econômica, por algumas décadas. E como obter monopólios? Claro que toda monopolização exige um papel fundamental dos governos, seja legislando ou decretando, seja impedindo outros governos de legislarem ou decretarem. Doutro lado, os capitalistas devem criar os canais culturais que favoreçam tais redes monopolísticas, e para isso necessitam do apoio dos criadores e sustentadores de padrões culturais. Tudo isso resulta em custos adicionais para os capitalistas. (Wallerstein, 1999, 230) 
Si durante finales de los años 40 e inicio de los 50 la CEPAL frenó los propósitos de liberalización de las barreras a las mercancías y capitales estadounidenses, proponiendo la sustitución de las importaciones, la reforma agraria y el fortalecimiento de un sistema bancario estatal y crediticio - que fue en buena medida, adoptada por los gobiernos latinoamericanos -, lo mismo no pasó en los años 70. El resultado fue la conformación de una estructura de mercado predominantemente en forma de oligopolios extranjeros y nacionales en los sectores tecnológicamente más avanzados y económicamente importantes.

De todo modo, si las empresas multinacionales de los países centrales se direccionaron hacia los países periféricos y semi-periféricos buscando una fuerza de trabajo con menor costo, lo mismo ocurrió con esas empresas una vez aquí operantes, en suelo nacional y, con las propias empresas de capital nacional. Todas ellas se direccionaron hacia el interior de Latinoamérica para reducir los costos de la fuerza de trabajo y los costos de transacción.

De esa forma, ¿qué tipo de desarrollo se establece en los marcos del capitalismo mundial? ¿Qué tipo de desarrollo se establece en los marcos de un capitalismo más regionalizado?

Como fue destacado anteriormente, las bases del desarrollo capitalista ya se encuentran en Ricardo, en especial, cuando se asume que la sociedad se organiza a partir de la propiedad de los factores productivos, con destaque para el capital. Esa ley una vez adoptada, como visto a través de Wallerstein, no podrá jamás conducir a un desarrollo económico que garantiza los derechos humanos elementales como la alimentación, habitación, salud y educación para la gente. Esto sucede porque las propuestas del desarrollo económico en el marco del capitalismo, han privilegiado la racionalidad de las ganancias y su maximización. De ahí, una empresa operante en un continente, un Estado-nación o en una región, al mirar hacia las ganancias tendrá que evaluar los costos de transacción y de fuerza de trabajo, y con esta evaluación, su permanencia en ese espacio estará garantizada apenas por los beneficios.

De esta manera, si las empresas visan el aumento de las ganancias buscando la reducción de los costos de la fuerza de trabajo en otras regiones, la explotación de los trabajadores en las zonas periféricas y semi-periféricas aumenta en comparación con los trabajadores del centro. Incluso parte de los 
beneficios destinados a los trabajadores del centro por las empresas capitalistas, se hace posible ya que en las otras dos zonas de la economía-mundo obtienen altas tasas de plusvalía.

Además, es un gran atractivo para los grandes grupos empresariales hacer la implantación de sus parques fabriles en regiones más periféricas, debido a que allí, en general, existen pocas barreras para la destrucción de la naturaleza. La posibilidad de externalización de los costos ambientales por las empresas, termina por transferir esos costos a los Estados nacionales y a las poblaciones locales. En esta dirección, vale observar que en nombre del desarrollo económico no existe obstáculo cuando los beneficios superan los costos, especialmente cuando la posibilidad de explotar nuevas fuentes de materia prima se hace presente. No es raro observar regiones deforestadas y poblaciones desplazadas debido a la explotación de algún mineral, a la expansión de la frontera agrícola, o debido a la ganadería.

Finalmente, es importante percibir que América Latina intenta en la actualidad direccionarse hacia el desarrollo y la integración a través de la formación de varios mercados comunes, destacándose el Mercosur. No obstante, es relevante observar la estructura de ese mercado común, que a su vez, se inspira en el mercado común europeo.

Las etapas que visan la integración, por la cual tendrán que pasar los países de ese mercado en construcción, se refieren a la gradual liberalización comercial, el establecimiento de un mercado común entre los países participantes, lo que significa la libre movilidad de los factores productivos capital y trabajo, bien como, a largo plazo el establecimiento de una unión monetaria y una moneda común.

Así, si por un lado la creación de los mercados comunes posibilitará el fortalecimiento de los países participantes del bloque, frente a la dinámica del mercado capitalista mundial contemporáneo, minimizando la transferencia de parte de la plusvalía hacia el centro a través de la implantación de un capitalismo regional y latinoamericano, de un sistema de crédito, infraestructura y cadenas mercantiles interconectadas, vale notar que la dinámica del desarrollo económico en curso ha mantenido los fundamentos de lo anteriormente expuesto.

Entonces, después de estos aportes, no se puede olvidar que la temática del desarrollo que surge después de la "crisis del consenso neoliberal" es 
vista por importantes teóricos latinoamericanos como una oportunidad para un pensamiento crítico propio:

Vuelve ahora a surgir, en el centro del sistema, una crisis del pensamiento hegemónico y, en América Latina, una nueva oportunidad de construir, como proponían Prebisch, Furtado y los otros fundadores del pensamiento crítico latinoamericano, nuestra propia visión del desarrollo y nuestra ubicación en el mundo. (Ferrer, 2012: 164).

\section{EL PLANTEO DEL BUEN VIVIR FRENTE LA LÓGICA DEL DE- SARROLLO CAPITALISTA: LÍMITES Y POTENCIALIDADES}

El planteo del Buen Vivir, movilizado inicial y principalmente por los movimientos indígenas en América Latina tiene un potencial alternativo y crítico hacia el consagrado concepto de desarrollo que le da una relevancia fundamental en cualquier propuesta de cambio profundo que pretenda enraizarse en una originalidad latinoamericana:

El Buen Vivir representa frente al desarrollo un cambio radical sobre nuestras ideas acerca del desarrollo. Es que el Buen Vivir no es solamente uno más entre otros "desarrollos alternativos", sino que pone en discusión toda la base conceptual del desarrollo occidental. (Gudynas, 2010: 43)

Para esclarecer el concepto de Buen Vivir comenzamos brindando algunas explicaciones de intelectuales indígenas:

Su verdadero significado, proviene del Quechua o Quichwa y contiene dos conceptos y expresiones como sigue: SUMAK y KAWSAY. SUMAK, significa plenitud, grandeza, lo justo, completamente, lo superior. KAWSAY, es vida en realización permanente, dinámica y cambiante. Es interacción de la totalidad de existencia en movimiento, la vida entendida desde lo integral, es la esencia de todo ser vital. Por tanto, Kawsay es, estar siendo. El Sumak Kawsay, es la vida en plenitud, es el resultado de la interacción, de la existencia humana y natural. Es decir, que el Sumak Kawsay es el estado de plenitud de toda la comunidad vital. Es la construcción permanente de todos 
los procesos vitales, en las que se manifiesta: la armonía, el equilibrio, interno y externo de toda la comunidad no solo humana, pero también natural. A esta orientación o sistema de vida, desde la concepción y práctica comunitario se le denomina la fase superior de la vida: el Kapak Ñan. (...) El Sumak Kawsay, es entonces, la vida en plenitud, o la vida en esplendor, expresa lo supremo, la vida en el sistema comunitario, armonía entre todos los seres considerados como sujetos. (Macas, 2010: 23-25).

Desde este planteo, Macas pone en discusión una traducción simple de este concepto andino por el de "Buen Vivir" (id. 24).

Es, entonces y antes que nada, un "sistema de vida ... comunitario" (Macas, 2010: 16), pero que no tiene como referencia sólo la comunidad humana, sino también a la Pachamama o Madre Naturaleza:

\begin{abstract}
Desde la visión de las Nacionalidades, lo comunitario está constituido por la comunidad humana y su entorno, o todos los elementos de la comunidad natural. Es decir, la comunidad humana y todas las formas de existencia, aquellos elementos vitales como parte esencial de la Naturaleza. Las Nacionalidades Originarias de estas regiones geográficas y políticas, nos consideramos una partícula que se gesta bajo el abrigo de la Pachamama. Es ésta, la concepción y práctica sobre la (Madre) Naturaleza. (Macas, 2010: 17)
\end{abstract}

El Buen Vivir es totalmente inescindible de la relación con la naturaleza entendida como Pachamama. En las sociedades indígenas no se provocó una "ruptura" con la Pachamama, sino que "se vive como parte de ella", ya que "su organización comunitaria, es el resultado de un proceso de experiencias y vivencias sociales milenarias desde la armonía con la Madre Naturaleza, históricamente determinados" (Macas, 2010: 16-17).

Así, esta concepción, políticamente expresada, va a derivar en una histórica plasmación constitucional que reconoce los Derechos de la Pachamama:

Que este artículo aparezca en la Constitución ecuatoriana es un evento político-epistémico que trastoca la historia moderna y a los políticos que la habitan -incluyendo las izquierdas-, porque desafía al liberalismo, al Estado y al capital. Ambas 
ideas - los derechos de la Pachamama y el buen vivir - se basan en nociones de vida en las que todos los seres (humanos o no humanos) existen siempre en relación entre sujetos -no entre sujeto y objeto, y de ninguna manera individualmenteLa relacionalidad que subyace a estas propuestas también explicaría el "mandar obedeciendo" zapatista, que busca evitar la separación entre la sociedad/comunidad y un ente que la representa. Constituye una fuerza vital para transformar las instituciones y hacer visible aquello que había sido producido como no creíble. (Escobar, 2011: 311).

Esta característica comunitaria y la de su relación a la Pachamama, tienen una dimensión que se podría llamar panétnica: "es un modo de vida de las civilizaciones de Abya Yala, donde se practica y aún pervive este sistema y concepción de vida" (Macas, 2010: 16).

El principio del Buen Vivir surge dentro de lo que Gudynas llama "paradigma biocéntrico", o sea, de entender que la centralidad referencial de todo el pensamiento inspirador de la acción y del conocimiento, no está en el hombre aislado, sino está en la vida entendida fundamentalmente desde la relacionalidad. Una relacionalidad integral que está condicionada a la vida de la Pachamama, "dentro de ella se generan las condiciones de armonía y el equilibrio para lograr la plenitud en toda la comunidad ampliada". Así, vida y comunidad están intrínsecamente unidos: "La vitalidad de todas las existencias constituye la vida y en esta relación vital se constituye la concepción y la práctica del sistema comunitario" (Macas, 2010: 21).

Se propone así, desde el concepto de Buen Vivir, una transformación civilizatoria que solo es posible desde la desmercantilización de la naturaleza reconociéndola como "sujeto":

(...) la desmercantilización de la Naturaleza se perfila como indispensable. Los objetivos económicos deben estar subordinados a las leyes de funcionamiento de los sistemas naturales, sin perder de vista el respeto a la dignidad humana y la mejoría de la calidad de vida de las personas. El crecimiento económico es apenas un medio, no un fin. (Acosta, 2010:18)

Para Macas, estas propuestas que se basan en contenidos étnicos ancestrales e indígenas, son propuestas destinadas a generar una alianza po- 
pular que trasciende cualquier clase de frontera cultural y, sostiene el autor, que esta alianza transcultural "es el resultado de las experiencias de lucha contra la colonialidad" (Macas, 2010: 14-15). Desde este mismo supuesto descolonizador, la propuesta del Buen Vivir resulto un "nuevo horizonte de sentido histórico (que) emerge con toda su heterogeneidad histórico/ estructural" (Quijano, 2010: 63).

Así, para Quijano, este planteo conlleva un cuestionamiento al poder, ósea,

\begin{abstract}
"como un complejo de prácticas sociales orientadas a la producción y a la reproducción democráticas de una sociedad democrática, un modo distinto de existencia social, con su propio y específico horizonte histórico de sentido, radicalmente alternativo, a la Colonialidad Global del Poder (entendida como las relaciones de poder en el mundo) y a la Colonialidad/ Modernidad/Eurocentrada" (Quijano, 2010: 48).
\end{abstract}

La autoridad del planteo del Buen Vivir no le viene de su modernidad, ni de la cientificidad occidental, sino por el contrario de su ancestralidad de la experiencia de vida: "Son experiencias históricas de vida, convertidas en propuestas, las que pueden convertirse en una opción de vida para la comunidad humana y la vida frente al modelo y el sistema en crisis" (Macas, 2010: 15). Por eso, desde esta "ancestralidad del saber" que cuestiona el modelo evolucionista y con pretensión de universalidad del saber moderno se plantea una descolonización epistémica que habilita para pensar el modelo político, social y económico mediante una "ruptura epistemológica" (Macas, 2010: 32).

Se trata, por fin, de un proyecto opuesto al capitalismo:

Desde nuestro entender el capitalismo persiste, cuya esencia del Capitalismo, es la acumulación. La acumulación es la razón de ser del modelo capitalista. La base fundamental que determina este modelo es la propiedad privada de los medios de producción, como hasta el momento existe, y es la privatización y mercantilización de la Madre Naturaleza, a lo que el capitalismo lo llama recursos naturales, (conceptos que provienen desde la consideración de objeto a la Naturaleza). Lo que para el mundo de Abya Yala es Pachamama, 
es un ser vivo, es Sagrada. Es aún más grave, cuando desde el pensamiento occidental, a los seres humanos se nos considera objetos, y se mercantiliza al convertirnos en recursos. Los seres humanos no somos recursos. Pues, este modelo a partir de esta consideración a los seres humanos, se sustenta en la explotación del trabajo del ser humano, en función de garantizar la acumulación, lo que explica, la libre oferta y demanda de la fuerza del trabajo humano, la explotación de la humanidad. Para que el sistema occidental sea reconocido y perfecto globalmente, el desarrollo económico, el crecimiento económico debe ser la fuente de la prosperidad, el bienestar sociedad. Pero este crecimiento económico es un sistema que está regulado por la libre oferta y demanda, es decir, bajo el control absoluto del mercado. Un mercado que rompe las barreras identitarias, civilizatorias que violenta y pulveriza las diversas formaciones y procesos sociales, y se afianza cada vez más su expansión en la explotación del trabajo humano, se sustenta en la competencia, lo que trae como consecuencia, entre otras causas, la agudización de la pobreza en el mundo. (Macas, 2010: 35-36).

Por lo tanto, el concepto retoma una dimensión ética que se opone a la explotación del hombre y de la naturaleza y desde allí se cuestiona el concepto de desarrollo en cuanto unido a esta explotación (Macas, 2010: 38). Así aparece la pregunta por la compatibilidad de ambos modelos:

La pregunta que cabe en este punto es si será posible y realista intentar un ordenamiento social diferente dentro del capitalismo. Se entiende uno fundamentado en la vigencia de los Derechos Humanos y de los Derechos de la Naturaleza. La respuesta es simple: no. Sin embargo, con la sola aceptación constitucional del Buen Vivir no se superará este sistema que es en esencia la civilización de la desigualdad. (Acosta, 2010:9)

De acuerdo con Macas, la propuesta incluye la descolonización del Estado, del conocimiento y del pensamiento, destruyendo incluso las bases epistémicas del capitalismo. En este cambio se encuentra el potencial efectivo para la garantía de los derechos humanos fundamentales como alimentación, salud, educación y habitación a la población. Se encuentra 
también la posibilidad de substituir la racionalidad de la producción de ganancias por la racionalidad de la producción de la vida. Eso significa que la preservación y valorización del ser humano y de la naturaleza podrán convertirse en slogan del desarrollo.

\section{CONSIDERACIONES FINALES}

La dinámica de construcción de un modelo de integración contrahegemónica en América Latina exige una discusión, un diálogo de saberes entre las distintas propuestas que aparecen como emancipadoras en nuestra región. La originalidad de la propuesta del Buen Vivir es apta para cuestionar profundamente el concepto de desarrollo en la línea de un horizonte superador del capitalismo, económica y culturalmente.

Se puede percibir que las bases de los modelos desarrollistas en la historia de Latinoamérica no rompieron la estructura epistémica que fundamenta la explotación capitalista. Claro está, que hubo gobiernos que implementaron políticas económicas que promocionaron un desarrollo económico, lo cual a su vez, trajo la inclusión de parte de la población que vino a conformar lo que actualmente se denomina clase media.

Todavía, un cambio efectivo no se produjo porque la racionalidad productiva volcada a la acumulación del capital, fue siempre el objetivo principal de esas políticas. Las capas bajas, como son denominadas por los medios de comunicación, ahora son conducidas a creer en la propuesta de integración en América Latina como una forma de inclusión social. ¿Eso será posible? Se constata que la integración de América Latina es posible, pero la inclusión social está lejos de concretizarse en los marcos de la integración propuesta. Eso se hace evidente porque las etapas más importantes de la integración en curso - liberalización comercial, unión aduanera, mercado común y unión monetaria - continúan valorizando la maximización de los factores productivos, en especial el capital.

En ese sentido, la academia latinoamericana tiene que asumir este debate y su profundización con urgencia, abriéndose a un proceso descolonizador de sus contenidos y de su institucionalidad. Ese es un largo camino, pero fundamental para la emancipación y afirmación de nuestra latinoamericanidad. 
Así, se considera la originalidad de la propuesta del Buen Vivir un importante paso hacia la construcción de este camino, pues cuestiona profundamente el concepto de desarrollo en la línea de un horizonte superador del capitalismo.

\section{ECONOMIC DEVELOPMENT AND/OR WELFARE: CURRENT LATIN-AMERICAN DILEMMA}

\section{Abstract}

Economic development and Welfare comes up on the Latin-American government perspectives that proclaim themselves as popular and aim the regional integration. The first one, raised on the capitalism, was adopted as condition and possibility synonym of an economic and political independence process. The second one emerged from the indigenous fights and ethical politics process that has been rising since the 80 's until molding as constitutional principles in some countries. In this way, the paper intends to show how both views are in conflict. If at the present capitalism stage in Latin America is evidenced a strong preoccupation from the governments in relation to economic integration it is realized through this work that the human rights assurance such as health, dwelling, education and food are far from giving the Welfare to the marginalized population as the development model rationality aims the profit production, when it should be guided to life production.

Keywords: Latin-American. Economic Development. Social Movements.

\section{BIBLIOGRAFÍA}

ACOSTA, Alberto (2010). El Buen Vivir en el camino del post-desarrollo. Una lectura desde la Constitución de Montecristi. Quito: FES-ILDIS.

ESCOBAR Arturo (2011). "Una minga para el posdesarrollo". Signo y Pensamiento 58- Puntos de vista, vol. XXX, enero-junio, p. 306-312. 
GROSFOGUEL, Ramón (2006). "La descolonización de la economía política y los estudios postcoloniales". Tabula Rasa, $\mathrm{N}^{\circ}$ 4, enero-junio, p. 15-46.

GUDYNAS, Eduardo (2010). "Buen Vivir: un necesario relanzamiento". Yachaykuna, $\mathrm{N}^{\circ}$ 13, Quito: ICCI, junio, p. 40-46.

MACAS, Luis (2010). "El Sumak Kawsay". Yachaykuna, № 13, Quito: ICCI, junio, p. 13-39.

QUIJANO, Aníbal (2010). “'Bien Vivir' para redistribuir el poder. Los pueblos indígenas y su propuesta alternativa en tiempos de dominación global..' Yachaykuna, $\mathrm{N}^{\circ}$ 13, Quito: ICCI, junio, p. 47-63.

RICARDO, David. Princípios de Economia Política e Tributação. São Paulo: Abril, 1983

WALLERSTEIN, Immanuel. "A reestruturação capitalista e o sistema-mundo”. In:GENTILLI, Pablo (Org.). Globalização excludente. Petrópolis, RJ: Vozes, 1999.

WALLERSTEIN, Immanuel. "Mundialização ou era de transição? Uma visão de longo prazo da trajetória do sistema-mundo" In:Chesnais, François et al. Uma nova fase do capitalismo? São Paulo, SP: Xamã, 2003.

WALLERSTEIN, Immanuel. Impensar a ciência social: os limites dos paradigmas do século XXI. Aparecida, SP: Idéias \& Letras, 2006. 